\title{
Adapting to the COVID-19 pandemic on Building Research in Diet and Cognition (BRIDGE) trial
}

Marian Fitzgibbon 1,2,3,4*, Lara Blumstein ${ }^{1}$, Linda Schiffer ${ }^{1}$, Mirjana A. Antonic ${ }^{1}$, Andrew McLeod ${ }^{1,5}$, Roxanne Dakers ${ }^{1}$, Leo Restrepo ${ }^{1}$, Elizabeth A. Boots ${ }^{1}$, Jennifer C. Sanchez-Flack ${ }^{1,2,4}$, Lisa Tussing-Humphreys ${ }^{1,4,5}$ and Melissa Lamar ${ }^{6}$

\begin{abstract}
Background: The COVID-19 pandemic has altered the research landscape for clinical trials, requiring thoughtful consideration regarding how to handle the risks and benefits of continuing them.

Design: This brief report describes the experience of adapting the Building Research in Diet and Cognition (BRIDGE) study, a randomized clinical trial examining the effects of the Mediterranean diet, with and without weight loss, on cognitive functioning in 185 older obese African American adults during the COVID-19 pandemic.

Measurement: The University of Illinois at Chicago (UIC) developed an expedited amendment process for research shifting to remote data collection. We conducted the study in three consecutive groups. For group 3, 14-month data collection period, we adapted our protocol to allow data collection via telephone and e-mail. We were unable to collect certain measures that required face-to-face contact.
\end{abstract}

Results: For measures that could be collected remotely, 14-month retention was similar for group 3 compared to groups 1 and 2: data were collected for $86.9 \%$ of group 3 (remote) and 87.9\% of groups 1 and 2 (face to face), $p=$ 84 .

Conclusions: In order to preserve the integrity of our clinical trial and ensure the safety of our participants and staff during the COVID-19 pandemic, we had to carefully and efficiently adapt our data collection procedures. The procedures put in place allowed us to collect our primary outcomes and the majority of our secondary outcomes and will enable us to examine the role of dietary intake, with and without weight loss, on cognitive functioning in a vulnerable and high-risk population.

Trial registration: ClinicalTrials.gov NCT3129048. Registration Date: 4/17/2017.

\footnotetext{
*Correspondence: mlf@uic.edu

Impact: Conducting clinical trials often requires adaptations to unforeseen

challenges. The COVID-19 pandemic has required thoughtful planning to

ensure the safety of study participants and staff.

${ }^{1}$ Institute for Health Research and Policy, University of Illinois at Chicago,

1747 West Roosevelt Road, Chicago, IL 60608, USA

${ }^{2}$ Department of Pediatrics, University of Illinois at Chicago, 1200 West

Harrison Street, Chicago, IL 60607, USA

Full list of author information is available at the end of the article
}

(c) The Author(s). 2021 Open Access This article is licensed under a Creative Commons Attribution 4.0 International License, which permits use, sharing, adaptation, distribution and reproduction in any medium or format, as long as you give appropriate credit to the original author(s) and the source, provide a link to the Creative Commons licence, and indicate if changes were made. The images or other third party material in this article are included in the article's Creative Commons licence, unless indicated otherwise in a credit line to the material. If material is not included in the article's Creative Commons licence and your intended use is not permitted by statutory regulation or exceeds the permitted use, you will need to obtain permission directly from the copyright holder. To view a copy of this licence, visit http://creativecommons.org/licenses/by/4.0/. The Creative Commons Public Domain Dedication waiver (http://creativecommons.org/publicdomain/zero/1.0/) applies to the data made available in this article, unless otherwise stated in a credit line to the data. 


\section{Introduction}

The COVID-19 pandemic changed how we work, socialize, and function on a day-to-day basis. At academic medical centers across the United States (US), the COVID-19 pandemic altered many rigorously planned research protocols of randomized clinical trials (RCTs) $[1,2]$. At the time of this writing, there were 364,274 registered studies listed on ClinicalTrials.gov [3]. This includes 156,181 drug or biologic, 66,769 surgical or device, and 93,750 behavioral trials [3]. Also, at the time of this writing, this worldwide pandemic has infected more than $167,405,137$ and killed more than 595,101 people in the US [4]. It was apparent that to preserve our trial's integrity, we needed to quickly adapt our data collection procedures given the final data collection period of our three-arm RCT was scheduled to begin in April to May of 2020, and we were unable to collect data in-person.

Briefly, the Building Research in Diet and Cognition (BRIDGE) trial is a three-arm RCT with 185 obese African American older adults (55-85 years of age) randomized to (1) a typical diet control, (2) a Mediterranean diet lifestyle intervention without caloric restriction (MedDiet-A), or (3) a Mediterranean diet with caloric restriction to promote weight loss (MedDiet-WL). The trial was designed to test whether MedDiet-WL would produce better results than a MedDiet-A on the primary outcome of cognitive functioning and secondary outcomes of body weight, body composition, dietary intake, lifestyle behaviors, and cardiometabolic-related biomarkers. Both MedDiet lifestyle interventions were 14 months long, including an 8-month, 27-session group intervention, followed by a 6-month minimal contact period. The design and baseline characteristics of the sample are described in detail elsewhere $[5,6]$.

Before beginning our final data collection period for our third and last group, many national organizations such as the National Institutes of Health (NIH), the Centers for Disease Control and Prevention (CDC), and the Office of Research and Development (ORD) had indicated research visits to be nonessential $[7,8]$. For trials funded through the NIH, it was advised that investigators work with their respective Institutional Review Boards (IRBs) to assess the appropriate measures in order to guarantee the protection of both research participants and study staff. At the BRIDGE study site, the University of Illinois at Chicago (UIC) IRB instituted a hold on human subject research, including in-person, face-to-face interaction that was not critical from a patient care perspective. The IRB instructions, however, did indicate that research that could be conducted remotely was potentially acceptable.

The purpose of this paper is to document our experience of adapting the BRIDGE research protocol during the COVID-19 pandemic to meet data collection requirements and retention expectations and ultimately to answer our research questions. The BRIDGE trial is registered at ClinicalTrials.gov (NCT03129048).

\section{Methods}

The BRIDGE Trial was conducted in three groups of approximately 60 persons each [5]. Participants provided data at baseline, immediately after the 8-month intervention, and at 14 months. Data collection assessed sociodemographic status, cognition, body weight, body composition, dietary intake, physical activity, cardiometabolic-related biomarkers, and health history. Prior to the pandemic onset, we were on course to begin our 14-month follow-up data collection for group 3 starting in April to May 2020.

The primary outcome of the study was change in cognitive functioning from baseline to post 8-month intervention. The cognitive assessment protocol was a 60min neuropsychological protocol consistent with that developed by the National Institute of Neurological Disorders and Stroke and the Stroke-Canadian Networks Neuropsychology working group [9]. The secondary outcomes were related to body weight measured using a digital scale (Tanita, Arlington Heights, IL), whole-body composition using the General Electric Lunar iDXA machine (GE Healthcare, US), and cardiometabolic risk markers, including cholesterol, insulin, and glucose measured by Quest Diagnostics (Wood Dale, IL). Dietary intake was assessed using the Harvard Food Frequency Questionnaire [10]. Participants were also asked to wear the Actigraph GT3X triaxial accelerometer [11] for 7 days to measure physical activity objectively. Functional capacity and mobility capacity were measured with the 6-min walk test $[5,12]$.

After the onset of the pandemic and associated restrictions to in-person, face-to-face human subject research interaction, we immediately began to plan how we could complete the RCT given the amount of time and effort staff and participants had contributed already as well as the scientific value of completing the study. Simultaneously, the UIC IRB developed an expedited amendment process specifically for changes to research caused by the COVID-19 shutdown.

The first step in adapting to the COVID-19 research restrictions was to review and verify the options we had for remote data collection. At the outset of the pandemic, only about half of our group 3 participants reported having reliable online access to face-to-face remote technology (e.g., Zoom) (www.Zoom.us). Therefore, we decided to conduct telephone interviews because all of our participants had phone access. To determine the feasibility of collecting data via telephone, staff practiced and timed this data collection procedure. Based on these practice interviews, it was decided that 
our 14-month follow-up data collection for group 3 could be completed over two sessions ( $1 \mathrm{~h}$ each) via telephone: one call would include lifestyle measures and dietary intake data collection, and the second call would collect data using a modified cognitive assessment protocol.

Data collection was conducted while all faculty and staff were working remotely. Cell phones, hot spots, and laptops were provided to the data collection team, as needed. The study coordinator received permission to enter the offices during the shutdown to prepare all data collection material for distribution to the data collection team; once compiled, it was safely dropped off with no contact. Once our new amendment, protocol, and the addendum to informed consent forms were finalized, submitted, and approved by the IRB, data collection began.

Most cognitive assessment measures were validated for remote collection [13] and able to be administered in the same fashion as had been done during in-person, face-to-face visits. One measure, the Trail Making Test, was adapted for oral administration via telephone as previously described and validated $[14,15]$. Two of the original BRIDGE neuropsychological protocol measures, i.e., Digit Symbol Coding [16] and the Stroop Color Word [17] measures, were excluded because a key aspect of administration involves the exchange of test forms for participant usage and completion (i.e., reading and/or writing). During practice interviews, we developed a detailed protocol for telephone cognitive assessments.

Data collection involving specific equipment was modified wherever possible to ensure the capture of these important outcomes. For example, we were able to remotely collect participant weight by mailing digital scales to each participant. Additionally, the study coordinator brought the necessary equipment for initializing, charging, and downloading accelerometers to the home of a staff member, who mailed accelerometers to group 3 participants and maintained contact with them via text messaging for the requisite 7 days of wear. The accelerometers were then returned to the staff member's home by US Mail. Because we were unable to meet participants in person, we did not collect blood samples, assess whole-body composition using iDXA, measure blood pressure, or assess functional capacity via the 6-min walk test.

\section{Results}

As seen in Table 1, study participants were at increased risk for COVID-19 due to age and co-morbid medical conditions. Specifically, the mean age was 66.4 years, and $26.2 \%$ were $\geq 70$ years. While all of the participants were obese (body mass index (BMI) $\geq 30 \mathrm{~kg} / \mathrm{m}^{2}$ ), $37.7 \%$ had class II obesity $\left(\mathrm{BMI}=35\right.$ to $\left.<40 \mathrm{~kg} / \mathrm{m}^{2}\right)$, and $27.9 \%$ had class III obesity (BMI $\geq 40 \mathrm{~kg} / \mathrm{m}^{2}$ ). Most participants had been diagnosed with high blood pressure (68.9\%), and many were diagnosed with high cholesterol (46.5\%) and type 2 diabetes (23.0\%).

As shown in Table 2, participation in remote data collection by group 3 at 14 months (final data collection) did not significantly differ from participation in face-toface, in-person data collection by groups 1 and 2 at 14 months. The only exception was the collection of accelerometer data, though the difference was not statistically significant $(63.9 \%$ for $\mathrm{C} 3$ vs. $77.4 \%$ for $\mathrm{C} 1+\mathrm{C} 2, \mathrm{p}=$ 0.052). As noted above, we could not collect blood samples, assess body composition, blood pressure, or complete the 6-min walk test.

\section{Discussion}

COVID-19 will not be the last regional, national, or international disruption that affects day-to-day life [18]. Clinical research studies must have the ability to adapt to such disruptions while respecting the safety and confidentiality of participants and staff. Researchers have an obligation to implement and measure the feasibility and scalability of new approaches and the impact of these new approaches on participants and communities. These data will provide the basis for further guidelines regarding how to conduct research during times of crisis [1].

The health inequities in the US that impact underrepresented communities existed prior to the COVID-19 pandemic [19]. In Chicago, African Americans make up $30 \%$ of the population; yet, they represent $50 \%$ of COVID-19 cases and approximately $70 \%$ of COVID-19 deaths, most of which are concentrated in the most vulnerable communities [20]. Given our involvement in these communities pre-pandemic and the trusting relationships we had built between staff and BRIDGE participants, there was strong motivation to complete our research work together. Group 3 participants had already completed the full 8-month intervention and post-intervention data collection. We clearly communicated our appreciation for the time participants were taking to provide follow-up data while living with the pandemic's ongoing day-to-day challenges. For example, we conducted wellness calls and discussed relevant nonresearch-related issues such as COVID-19 safety precautions. In our interactions with our older adult participants, many of whom lived alone, most reported remaining at home and in contact with friends and family via phone and text messaging.

In retrospect, there could have been changes to data collection that may have been easier for participants. For example, many participants reported phone interview fatigue, as data collection lasted approximately $2 \mathrm{~h}$ over two sessions. Perhaps participants could have selfadministered their dietary intake and lifestyle measures 
Table 1 Participant characteristics at baseline, group 3

\begin{tabular}{|c|c|c|c|}
\hline & Number & Mean or \% & SD or $\mathrm{N}$ \\
\hline Age at randomization, years & 61 & 66.4 & $(6.2)$ \\
\hline $55-69$ & & $73.8 \%$ & (45) \\
\hline$\geq 70$ & & $26.2 \%$ & (16) \\
\hline Gender & 61 & & \\
\hline Female & & $93.4 \%$ & (57) \\
\hline Male & & $6.6 \%$ & (4) \\
\hline Race & 61 & & \\
\hline Black or African-American, not Hispanic & & $91.8 \%$ & (56) \\
\hline Hispanic & & $1.6 \%$ & (1) \\
\hline Native American & & $1.6 \%$ & (1) \\
\hline Multiracial & & $4.9 \%$ & (3) \\
\hline Marital status & 61 & & \\
\hline Single & & $13.1 \%$ & (8) \\
\hline Married & & $36.1 \%$ & (22) \\
\hline Widowed & & $21.3 \%$ & (13) \\
\hline Divorced & & $29.5 \%$ & (18) \\
\hline \multicolumn{4}{|l|}{ Medical conditions } \\
\hline High blood pressure & 61 & $68.9 \%$ & $(42)$ \\
\hline High cholesterol & 61 & $47.5 \%$ & (29) \\
\hline Type 2 diabetes & 61 & $23.0 \%$ & (14) \\
\hline Sleep apnea & 61 & $24.6 \%$ & (15) \\
\hline Weight, kg & 61 & 102.1 & $(15.3)$ \\
\hline Height, cm & 61 & 164.5 & (6.8) \\
\hline $\mathrm{BMI}, \mathrm{kg} / \mathrm{m}^{2}$ & 61 & 37.8 & $(5.5)$ \\
\hline BMI category & 61 & & \\
\hline Obesity class I (30 to $<35 \mathrm{~kg} / \mathrm{m}^{2}$ ) & & $34.4 \%$ & (21) \\
\hline Obesity class II (35 to $<40 \mathrm{~kg} / \mathrm{m}^{2}$ ) & & $37.7 \%$ & (44) \\
\hline Obesity class III ( $\geq 40$ kg/m²) & & $27.9 \%$ & (17) \\
\hline Percent body fat & 60 & 48.5 & $(5.1)$ \\
\hline
\end{tabular}

Table 2 Participation in 14-month ${ }^{\text {a }}$ data collection by group 3 compared to groups 1 and 2

\begin{tabular}{|c|c|c|c|c|c|}
\hline & \multicolumn{2}{|c|}{$C 3(N=61)$} & \multicolumn{2}{|c|}{$\mathrm{C} 1+2(\mathrm{~N}=124)$} & \multirow[t]{2}{*}{$p^{b}$} \\
\hline & $\%$ & $\mathbf{N}$ & $\%$ & $\mathbf{N}$ & \\
\hline$\overline{\text { Any data }}{ }^{c}$ & $86.9 \%$ & 53 & $87.9 \%$ & 109 & 0.84 \\
\hline Cognitive measures & $77.0 \%$ & 47 & $78.2 \%$ & 97 & 0.86 \\
\hline Diet intake & $86.9 \%$ & 53 & $87.1 \%$ & 108 & 0.97 \\
\hline Weight & $82.0 \%$ & 50 & $85.5 \%$ & 106 & 0.54 \\
\hline Lifestyle questionnaires & $86.9 \%$ & 53 & $87.9 \%$ & 109 & 0.84 \\
\hline Accelerometer & $63.9 \%$ & 39 & $77.4 \%$ & 96 & 0.052 \\
\hline
\end{tabular}

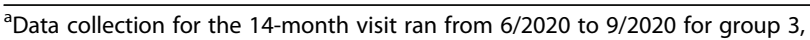
from $5 / 2019$ to $9 / 2019$ for group 2 , and from $6 / 2018$ to $10 / 2018$ for group 1

${ }^{b}$ From the chi-square tests for the differences between group 3 and group 1

$+2$

'Includes only measures collected at the 14-month visit for group 3: cognitive, diet, weight, questionnaires, and accelerometer via either a postage-paid return envelope system or an online portal. We could have further explored using online platforms, but not all participants had regular online access, and at the beginning of the pandemic, there were some concerns regarding maintaining confidentiality. However, since the start of the pandemic, many of these video platforms have increasingly improved their security measures. Additionally, given that most of our participants had smartphones, we could have further explored using REDCap surveys online. Nevertheless, compared to in-person assessments pre-pandemic that required multiple visits to our offices and a minimum of $3 \mathrm{~h}$ of data collection, remote assessments were likely easier for older participants. This could portend the greater use of remote assessments even after the COVID-19 pandemic ends. 
The COVID-19 pandemic has disrupted many research activities. Researchers need to utilize existing communication platforms (e.g., text messaging, email, and remote data collection) while, first and foremost, protecting the safety of study participants and staff [18]. We are currently analyzing our data, having successfully collected the majority of our primary outcome cognitive data and our secondary weight, dietary intake, physical activity, and lifestyle behavior data. Given the dearth of effective pharmacological treatments to prevent or halt cognitive decline, particularly in at-risk obese African American older adults [21-23], and even in the face of this global pandemic, this study has the potential to provide important insights regarding the role of lifestyle in maintaining cognitive health in aging populations [2426].

\section{Acknowledgements}

The authors would like to acknowledge study participants for giving generously of their time and effort on this study. We would also like to thank John Healy, General Manager at Columbus Vegetable Oils, and Judy Scott-McKay of the Almond Board of California for their contribution of olive oil and almonds, respectively, to the study. This work was supported by the National Heart Lung and Blood Institute of the National Institutes of Health [R01HL129153].

\section{Authors' contributions}

MF-conception and design and drafted the manuscript. LB — substantial contributions to the conception and methods. LS — conducted the analyses and interpretation of data. MA—substantial contribution to revisions. $\mathrm{AM}$ — design and contribution to revisions. RD — contribution to methods. LR — contribution to methods. EB — contribution to methods.

JSF-substantively revised the manuscript. LTH—substantively revised the manuscript. ML - contributed to design and substantively revised the manuscript. The authors read and approved the final manuscript.

\section{Funding}

National Heart Lung and Blood Institute

\section{Availability of data and materials}

The datasets used and/or analyzed during the current study are available from the corresponding author on reasonable request.

\section{Declarations}

\section{Ethics approval and consent to participate}

The BRIDGE Trial was approved by the University of Illinois at Chicago (UIC) Institutional Review Board. The trial is registered at ClinicalTrials.gov (NCT3129048)

\section{Consent for publication}

Not applicable

\section{Competing interests}

The authors declare that they have no competing interests.

\section{Author details}

'Institute for Health Research and Policy, University of Illinois at Chicago, 1747 West Roosevelt Road, Chicago, IL 60608, USA. ${ }^{2}$ Department of Pediatrics, University of Illinois at Chicago, 1200 West Harrison Street, Chicago, IL 60607, USA. ${ }^{3}$ School of Public Health, University of Illinois at Chicago, 1603 W Taylor St, Chicago, IL 60612, USA. ${ }^{4}$ University of Illinois Cancer Center, University of Illinois at Chicago, 818 South Wolcott Avenue, Chicago, IL 60612, USA. ${ }^{5}$ Department of Kinesiology and Nutrition, University of Illinois at Chicago, 1919 W. Taylor St, Chicago, IL 60612, USA. ${ }^{6}$ Rush
Alzheimer's Disease Center, Rush University, 1750 West Harrison Street, Chicago, IL 60612, USA.

Received: 2 March 2021 Accepted: 28 May 2021

Published online: 16 July 2021

\section{References}

1. McDermott MM, Newman AB. Preserving clinical trial integrity during the coronavirus pandemic. JAMA. 2020;323(21):2135-6. https://doi.org/10.1001/ jama.2020.4689.

2. Coleman BC, Kean J, Brandt CA, Peduzzi P, Kerns RD. Adapting to disruption of research during the COVID-19 pandemic while testing nonpharmacological approaches to pain management. Transl Behav Med. 2020;10(4):827-34. https://doi.org/10.1093/tbm/ibaa074.

3. Trends, Charts, and Maps. (2021). ClinicalTrials.gov. Accessed on January 22, 2021. Retrieved from https://clinicaltrials.gov/ct2/resources/trends.

4. WHO coronavirus disease (COVID-19) dashboard. (2020). Geneva: World Health Organization. Accessed on January 19, 2021. Retrieved from https:// covid19.who.int/.

5. Tussing-Humphreys L, Lamar M, Blumenthal JA, Babyak M, Fantuzzi G, Blumstein $L$, et al. Building research in diet and cognition: the BRIDGE randomized controlled trial. Contemp Clin Trials. 2017:59:87-97. https://doi. org/10.1016/j.cct.2017.06.003

6. Sanchez-Flack JC, Tussing-Humphreys L, Lamar M, Fantuzzi G, Schiffer L, Blumstein $L$, et al. Building Research in Diet and Cognition (BRIDGE): baseline characteristics of older obese African American adults in a randomized controlled trial to examine the effect of the Mediterranean Diet with and without weight loss on cognitive functioning. Prev Med Rep. 2020;22:101302. https://doi.org/10.1016/j.pmedr.2020.101302.

7. COVID-19. Center for Disease Control and Prevention. Accessed on January 12, 2021. Retrieved from https://www.cdc.gov/coronavirus/2019-ncov/index. html

8. Coronavirus Disease 2019 (COVID-19): Information for NIH applicants and recipients of $\mathrm{NIH}$ funding. National Institutes of Health. Accessed on January 12, 2021. Retrieved from https://grants.nih.gov/grants/natural_disasters/ corona-virus.htm.

9. Hachinski V, ladecola C, Petersen RC, Breteler MM, Nyenhuis DL, Black SE, et al. National Institute of Neurological Disorders and Stroke-Canadian stroke network vascular cognitive impairment harmonization standards. Stroke. 2006;37(9):2220-41. https://doi.org/10.1161/01.STR.0000237236. 88823.47.

10. Willett WC, Sampson L, Stampfer MJ, Rosner B, Bain C, Witschi J, et al. Reproducibility and validity of a semiquantitative food frequency questionnaire. Am J Epidemiol. 1985;122(1):51-65. https://doi.org/10.1093/ oxfordjournals.aje.a114086

11. Santos-Lozano A, Marín PJ, Torres-Luque G, Ruiz JR, Lucía A, Garatachea N. Technical variability of the GT3X accelerometer. Med Eng Phys. 2012;34(6): 787-90. https://doi.org/10.1016/.medengphy.2012.02.005.

12. ATS Committee on Proficiency Standards for Clinical Pulmonary Function Laboratories. ATS statement: guidelines for the six-minute walk test. Am J Respir Crit Care Med. 2002;166(1):111-7. https://doi.org/10.1164/ajrccm.1 66.1.at1102.

13. Wilson RS, Leurgans SE, Foroud TM, Sweet RA, Graff-Radford N, Mayeux R, et al. Telephone assessment of cognitive function in the late-onset Alzheimer's disease family study. Arch Neurol. 2010;67(7):855-61. https://doi. org/10.1001/archneurol.2010.129.

14. Ricker JH, Axelrod BN. Analysis of an oral paradigm for the Trail Making Test. Assessment. 1994;1(1):47-51. https://doi.org/10.1177/1073191194001001007.

15. Kaemmerer T, Riordan P. Oral adaptation of the trail making test: a practical review. Appl Neuropsychol Adult. 2016;23(5):384-9. https://doi.org/10.1 080/23279095.2016.1178645.

16. Wechsler D. Wechsler Memory Scale (3rd ed.). San Antonio, TX: Psychological Corporation; 1997.

17. Stroop JR. Studies of interference in serial verbal reactions. J Exp Psychol. 1935;18(6):643-62. https://doi.org/10.1037/h0054651.

18. Singh JA, Bandewar SV, Bukusi EA. The impact of the COVID-19 pandemic response on other health research. Bull World Health Organ. 2020;98(9):62531. https://doi.org/10.2471/BLT.20.257485.

19. Alcendor DJ. Racial disparities-associated COVID-19 mortality among minority populations in the US. J Clin Med. 2020;9(8):2442. https://doi.org/1 0.3390/jcm9082442. 
20. Reyes C, Husain N, Gutowski C, St Clair, S., \& Pratt, G. Chicago's coronavirus disparity: Black Chicagoans are dying at nearly six times the rate of white residents, data show. Chicago Tribune. 2020, 7.

21. Shadlen MF, Siscovick D, Fitzpatrick AL, Dulberg C, Kuller LH, Jackson S. Education, cognitive test scores, and black-white differences in dementia risk. J Am Geriatr Soc. 2006;54(6):898-905. https://doi.org/10.1111/j.1532-541 5.2006.00747.x

22. Mehta KM, Simonsick EM, Rooks R, Newman AB, Pope SK, Rubin SM, et al. Black and white differences in cognitive function test scores: what explains the difference? J Am Geriatr Soc. 2004;52(12):2120-7.

23. Rovner BW, Casten RJ, Harris LF. Cultural diversity and views on Alzheimer's disease in older African Americans. Alzheimer Dis Assoc Disord. 2013;27(2): 133-7. https://doi.org/10.1097/WAD.0b013e3182654794.

24. Lourida I, Soni M, Thompson-Coon J, Purandare N, Lang IA, Ukoumunne OC, et al. Mediterranean diet, cognitive function, and dementia: a systematic review. Epidemiology. 2013;24(4):479-89. https://doi.org/10.1097/ EDE.0b013e3182944410.

25. Valls-Pedret C, Ros E. Commentary: Mediterranean diet and cognitive outcomesEpidemiological Evidence Suggestive, Randomized Trials Needed. Epidemiology. 2013;24(4):503-6. https://doi.org/10.1097/EDE.0b013e3182 96bf8e.

26. Rolland Y, van Kan GA, Vellas B. Healthy brain aging: role of exercise and physical activity. Clin Geriatr Med. 2010;26(1):75-87. https://doi.org/10.1016/j. cger.2009.11.002

\section{Publisher's Note}

Springer Nature remains neutral with regard to jurisdictional claims in published maps and institutional affiliations.

Ready to submit your research? Choose BMC and benefit from:

- fast, convenient online submission

- thorough peer review by experienced researchers in your field

- rapid publication on acceptance

- support for research data, including large and complex data types

- gold Open Access which fosters wider collaboration and increased citations

- maximum visibility for your research: over $100 \mathrm{M}$ website views per year

At $\mathrm{BMC}$, research is always in progress.

Learn more biomedcentral.com/submissions 